\title{
Sensorial and Volatile Analysis of Wines Made from Partially Dehydrated Grapes: An Ontario Case Study
}

\author{
Jennifer M. Kelly $\mathbb{D},{ }^{1}$ Debra L. Inglis $\mathbb{D}^{1,},{ }^{1,2,3}$ and Gary J. Pickering $\mathbb{C}^{2,3,4,5}$ \\ ${ }^{1}$ Centre for Biotechnology, Brock University, St. Catharines L2S3A1, Canada \\ ${ }^{2}$ Cool Climate Oenology and Viticulture Institute, Brock University, St. Catharines L2S3A1, Canada \\ ${ }^{3}$ Department of Biological Sciences, Brock University, St. Catharines L2S3A1, Canada \\ ${ }^{4}$ Sustainability Research Centre, University of the Sunshine Coast, Sippy Downs 4558, Australia \\ ${ }^{5}$ National Wine and Grape Industry Centre, Charles Sturt University, Wagga Wagga 2678, Australia \\ Correspondence should be addressed to Gary J. Pickering; gpickering@brocku.ca
}

Received 31 August 2020; Revised 11 November 2020; Accepted 4 December 2020; Published 24 December 2020

Academic Editor: Fabio Napolitano

Copyright (c) 2020 Jennifer M. Kelly et al. This is an open access article distributed under the Creative Commons Attribution License, which permits unrestricted use, distribution, and reproduction in any medium, provided the original work is properly cited.

\begin{abstract}
Winemaking in cool climate viticultural areas can pose challenges due to difficulties in achieving optimal ripeness from climatic conditions that tend to vary vintage-to-vintage. To stabilize quality, the use of partially dehydrated grapes has been indicated as beneficial to the production of high-quality wine ("appassimento" style) despite climatic variation. Postharvest wine grape dehydration is a complex process that involves the concentration or formation of sugars, aromas, and flavours. One of the quality challenges facing appassimento style winemaking is elevated levels of undesirable oxidation compounds. The aim of this study was to characterize wines made from a local yeast isolate, Saccharomyces uvarum $\mathrm{CN} 1$, which demonstrates limited osmotolerance and may have application to this wine style, as it is a known lower producer of such compounds. Wines made with CN1 were compared to wines made with the accepted commercial standard, S. cerevisiae, EC1118. Fermentations $(n=24)$ were established at three target starting sugar concentrations from dehydrated Cabernet franc grapes $\left(24.5,26.0\right.$, and $27.5^{\circ}$ Brix $)$ and a control $\left(21.5^{\circ} \mathrm{Brix}\right)$ and were assessed for volatile organic compound (VOC) composition via gas chromatography-mass spectrometry (GC-MS). Wines also underwent quantitative descriptive analysis to identify and quantify sensory attributes by a trained panel $(n=11)$. Results show that the wines fermented with the yeast isolate contain significant differences in the concentrations of VOCs in the wines. Sensorially, the wines differed in intensity for a number of attributes, including red fruit aroma, black fruit flavour, and length of finish both within Brix treatments and amongst yeast strains. The most important differentiating factor amongst these wines was the combination of yeast strain at the highest starting sugar concentration $\left(27.5^{\circ} \mathrm{Brix}\right)$. These findings may assist winemakers by informing the yeast strain choice for optimizing appassimento style wine quality in cool climates.
\end{abstract}

\section{Introduction}

Wine aroma and flavour are important factors that influence quality. Wine is a complex matrix, with many suprathreshold odorants and nonimpact compounds simultaneously contributing to its aroma [1].

The aromatic volatile compounds of both grapes and wine associated with a wine's sensory quality are critical components of consumer response and acceptance [2-4].

Volatile compounds in wine originate in the grape berry, which can depend on cultivar, viticultural, and vinification techniques. They can also come from yeast and bacterial metabolism, as well as postfermentative treatments such as oak wood extraction. Finally, several important odorants can also form from chemical reactions during storage and aging. The compounds that form along the vine to glass continuum result in a diverse range of aroma and flavour profiles and contribute to the complexity of wine [5-7].

Postharvest practices such as grape dehydration have a concentration effect on sugar and volatile compounds and impact the final wine aroma and flavour $[8,9]$. Differences in the grape cultivars used, the postharvest drying environment 
of the grapes, fermentation conditions, winemaking method, and aging time influence the chemical and sensory characteristics of wines made from dehydrated grapes [10]. Partial grape dehydration to produce special or diversified wines is used in winemaking regions globally [11]. In Ontario, a cool climate grape growing and winemaking region of Canada, this winemaking style is emerging as a mitigation technique to combat viticultural difficulties associated with a changing climate [12, 13]. Drying grapes postharvest in an enclosed environment allows for protection from predators and extreme weather events that can negatively impact fruit and wine quality. Production of highquality red wine in suboptimal vintages where cold weather does not provide desirable conditions can be challenging. As a mitigation technique, the appassimento process, vinifying grapes that have been dried postharvest, may be beneficial to quality. The benefits of producing wines in the appassimento style include a change in organoleptic profile, resulting in riper flavours [14] that, perhaps, garner consumer appeal. However, wines produced from partially dehydrated grapes may contain high initial concentrations of oxidation compounds such as acetic acid, acetaldehyde, and ethyl acetate that arise during the drying process [14], as well as during high sugar fermentation, which may be associated with reduced wine quality. Yeast choice may be particularly important in this regard, as low oxidation compoundproducing yeast may potentially mitigate this problem.

A local isolated yeast-Saccharomyces uvarum $\mathrm{CN} 1$ (CN1) - has been utilized in microvinification trials to ferment appassimento grapes, that may positively influence the wine quality by significantly reducing the concentration of oxidation compounds in the final wine. Two previous studies over two vintages $[12,13]$ have confirmed that $\mathrm{CN} 1$ is a significantly lower producer of such compounds in both appassimento style and table wines. It remains to be elucidated, however, what CN1's sensorial impact is on the final wine quality. The impact of yeast in winemaking is crucial to the final aroma composition [15]. Alcoholic fermentation produces secondary metabolites such as acids, esters, aldehydes, and other volatile compounds (VOCs) that contribute to the uniqueness of wine's organoleptic profile, and the composition of these VOCs varies with the choice of yeast $[16,17]$.

The primary aim of this study was to characterize CN1 in wine made from partially dehydrated Cabernet franc grapes with respect to VOCs, volatile fatty acids (VFAs), and organoleptic properties. Cabernet franc grapes were chosen for this study, as they are a commonly grown variety in Ontario. A comparison is provided with the widely used commercial yeast S. cerevisiae EC1118. The secondary aim was to determine the influence of the starting sugar concentration $\left(21.5^{\circ}\right.$ Brix (control), $24.5^{\circ}$ Brix, $26.0^{\circ}$ Brix, and $27.5^{\circ}$ Brix) on these measures. This study provides novel information on the autochthonous yeast $\mathrm{CN1}$ and its application in the winemaking process using partially dehydrated grapes, which may assist in developing this wine style in Ontario and other wine regions with highly variable growing conditions. Additionally, determining the sensory profile of this wine made with a local yeast and local grapes represents an opportunity to develop a regional signature in Ontario appassimento style wine.

\section{Materials and Methods}

2.1. Winemaking. Wines were made with Cabernet franc grapes from the subappellation of Niagara-on-the-Lake after partial postharvest dehydration to their respective starting sugar concentration targets $\left(24.5,26.0\right.$, and $\left.27.5^{\circ} \mathrm{Brix}\right)$, while control grapes $\left(21.5^{\circ}\right.$ Brix $)$ were harvested and processed immediately. Grapes were dried in a barn dedicated to commercial appassimento grape drying. The drying barn did not have internal temperature and humidity regulation available. The barn was moderately susceptible to external temperature conditions as the barn was not insulated. Stand up fans were placed strategically throughout the facility to promote airflow. The drying time was 31 days to reach $24.5^{\circ}$ Brix (original weight $197 \mathrm{~kg}$ and postdrying weight $146 \mathrm{~kg}$ ), 37 days to reach $26.0^{\circ}$ Brix (original weight $215 \mathrm{~kg}$ and postdrying weight $164 \mathrm{~kg}$ ), and 61 days to reach $27.5^{\circ}$ Brix (original weight $226 \mathrm{~kg}$ and postdrying weight $158 \mathrm{~kg}$ ). These sugar targets were selected based on the results of a previous study [12], that indicated $28.0^{\circ}$ Brix was too high for $\mathrm{CN} 1$ to ferment wine to dryness $(<5 \mathrm{~g} / \mathrm{L}$ residual sugar), and thus, a lower upper limit and additional range was selected.

Wines were fermented in triplicate with either the commercially available $S$. cerevisiae EC1118 (Lallemand Inc., Montreal, QC) or the autochthonous S. uvarum CN1 yeast until dry. Details on taxonomy of $\mathrm{CN} 1$ are given in [13]. S. cerevisiae EC1118 was rehydrated according to manufacturer's directions and plated out on yeast extract peptone dextrose plates (YPD; $1 \%$ yeast extract, $2 \%$ peptone, $2 \%$ dextrose, and 2\% agar). CN1 yeast was prepared from a frozen glycerol stock and also plated out on YPD plates. Both yeasts were grown to appropriate colony size prior to preparing a starter culture in sterile-filtered grape juice. The starter cultures were built up in sterile-filtered Cabernet franc must and then followed a stepwise acclimatization procedure as outlined in [18]. Detailed winemaking methods are fully described in [13]. After fermentation was complete ( $<5 \mathrm{~g} / \mathrm{L}$ residual sugar) as determined by Megazyme kit (Megazyme International Ireland, Limited, Bray Company; Wicklow, Ireland), fermentation replicates were pressed separately with a small bladder press (Enotecnica Pillan, Vicenza, Italy) at one bar for two minutes into glass carboys. After filtering (pad filtered, 0.45 micron), wines were bottled into $750 \mathrm{~mL}$ glass bottles, closed with a natural cork, and stored in the wine cellar at the Cool Climate Oenology and Viticulture Institute (CCOVI) at Brock University at $15^{\circ} \mathrm{C}$ and $74.5 \%$ humidity.

2.2. Descriptive Analysis. A prior triangle test [12] demonstrated significant differences $(p<0.001)$ in wines made from partially dehydrated grapes produced with $\mathrm{CN} 1$ and EC1118, indicating that a descriptive analysis could be conducted. In a preliminary bench tasting, wines fermented at 26.0 and $27.5^{\circ}$ Brix starting sugar concentration were 
mostly representatives of the appassimento style, while $24.5^{\circ}$ Brix wines were perceptibly indistinguishable from the table wine. Thus, the wines included in the descriptive analysis were control, $26.0^{\circ}$ Brix, and $27.5^{\circ}$ Brix treatments. The 18 control and wines made from partially dehydrated grapes (vinified in triplicate, with either EC1118 or CN1) were sensorially evaluated by a trained panel of 11 volunteers (three males and eight females) recruited from students and staff at CCOVI four months after bottling. Data collection was conducted after a total of ten training sessions. All panellists had a previous wine tasting experience and were selected based on their interest and availability. Research ethics clearance was granted by the Research Ethics Office (file no. 14-021-INGLIS) at Brock University. The quantitative descriptive analysis methods followed the Manual on Descriptive Analysis Testing for Sensory Evaluation [19].

Consensus terminology, language training, and scoring wines on the scale and reference standards were developed over eight two-hour training sessions. During the first two training sessions, all wines were presented to the panel. Wine bottles were opened approximately 60 minutes before the training sessions began and were assessed for nontreatmentrelated faults such as cork taint. A descriptor list for aroma, flavour, and oral sensations and prototypical tastes was generated in the first two training sessions, and the descriptor list was eventually reduced through panel discussion to avoid redundant or overlapping terms. The final descriptor list is as follows: cherry, green pepper, black fruit, herbal, spice, green vegetal, fresh/dried/cooked red fruit, leather/meat, earthy/toast, floral, and candy/confection for aroma modalities and cooked/dried/fresh red fruit, confection, black fruit, spice, vegetal, herbal, and earthy/toast for flavour modalities, as well as astringency, alcohol, acidity, bitterness, and length of finish for oral sensation and prototypical taste modalities. After the descriptors were agreed upon by the panel, reference standards were presented for all aroma descriptors, and the subsequent training sessions optimized the standards to match the descriptors present in the wine. The final reference standards were made according to recipes outlined in Table 1, with the base wine consisting of the $24.5^{\circ}$ Brix starting sugar concentration Cabernet franc appassimento style wine.

Panel performance was evaluated throughout training. Panellists rated the intensity of the attributes on $15 \mathrm{~cm}$ line scales divided into quadrants and anchored with the terms low intensity and high intensity on paper ballots. After eight sessions, the panel performance was considered adequate, as descriptors were being rated in a uniform manner. Before data collection, participants completed two additional training sessions on the Compusense ${ }^{\mathrm{TM}}$ system to become familiar with the sensory booths and electronic data collection method.

Following training, panellists evaluated the 18 wines in duplicate over two sessions with three flights per session and six wines per flight using a complete randomized block design.

The flights were scheduled over three two-hour intervals, with a forced three-minute break between wines to prevent fatigue. Wine bottles were opened one hour the before sessions began and were assessed for nontreatment-related faults. Descriptive analysis data were collected using Compusense $^{\mathrm{TM}}$ (version 5) software (Guelph, ON, Canada). Panellists assessed the wines on digital $15 \mathrm{~cm}$ anchored line scales divided into quadrants and anchored with the terms low intensity and high intensity. One ounce $(30 \mathrm{~mL})$ of each wine was poured at room temperature into International Standards Organization wine glasses labelled with a threedigit blinding code and were covered with plastic lids (Petri dishes). The tastings and data collection took place in the sensory lab at CCOVI, and each participant sat in their own booth equipped with a computer screen, mouse, wines, unsalted crackers, water, and a cup for expectorating. Participants were encouraged to consume crackers and water between wines to cleanse palates and were required to expectorate wine samples after tasting. The lab was illuminated with red lights to correct for colour bias.

\subsection{Analysis and Quantification of Volatile Organic Com-} pounds and Volatile Fatty Acid Compounds. Analysis of compounds (Table S1) was conducted using the method outlined in [20]. These compounds were selected as they are representatives of several classes of volatile compounds previously identified as important to wine flavour [21]. Concentrations of standards were prepared based on [20] but were adjusted based on preliminary measurements of wines in this study. To summarize, the analysis was conducted using gas chromatography-mass spectrometry (GCMS), with volatile extraction performed using solid-phase microextraction (SPME) and a $2 \mathrm{~cm}$ divinylbenzene/carboxen/polydimethylsiloxane 23-gauge SPME fiber (Supelco Inc., Bellefonte, PA, USA). Compound separation and identification were achieved using an Agilent 7890A Gas Chromatograph (GC) coupled with an Agilent MS 5975 Mass Spectrophotometer (MS). The GC was equipped with a Deans Switch and two columns: a HP-5MS, (5\% phenyl)methyl siloxane column $(30 \mathrm{~m}, 0.25 \mathrm{~mm}$ i.d., $0.25 \mu \mathrm{m}$ film thickness) coupled with a secondary DB-Wax capillary column $(30 \mathrm{~m}, 0.25 \mathrm{~mm}$ i.d., $0.25 \mu \mathrm{m}$ film thickness) (J\&W Scientific). The analytical data software (Chemstation, MSD E.02.00.493 by Agilent Technologies) was used to extract the quantifying ions, and the ratio of the standard over the internal standard was plotted against each analyte concentration to fit a quadratic equation. Compounds were quantified by comparison of the retention time and mass spectra (Chemstation/Wiley spectral databases, NIST 08) to pure standards (Table S1). Six-point calibration curves were run for each compound in model wine solution to ensure linearity $\left(r^{2}>0.9\right.$, Table S2). Standard curve concentrations were quantified based on the ratio of the peak area of the compound relative to the peak area of the deuterated internal standards to determine the concentration of the analytes. Analysis was run in duplicate with coefficient of variation between replicates ranging from $2-18 \%$.

2.4. Identification and Quantification. The analytical data software (Chemstation, MSD E.02.00.493 by Agilent Technologies) was used to extract the quantifying ions, and the 
TABLE 1: Reference standards and descriptors used for sensory analysis of wines made from partially dehydrated grapes.

\begin{tabular}{|c|c|c|}
\hline Descriptor & Includes attributes & Reference standard composition \\
\hline Green pepper & & $50 \mathrm{~mL}$ wine + one drop of "green pepper" aroma* \\
\hline Spice & $\begin{array}{l}\text { Black pepper, baking spice, and } \\
\text { anise }\end{array}$ & $\begin{array}{l}50 \mathrm{~mL} \text { wine }+ \text { four crushed all spice balls }+ \text { one drop "anise" aroma* }+ \text { two } \\
\text { shakes of black pepper }\end{array}$ \\
\hline $\begin{array}{l}\text { Red fruit (cooked/ } \\
\text { dried/fresh) }\end{array}$ & $\begin{array}{l}\text { Cherry, strawberry, raspberry, } \\
\text { cranberry, and jam }\end{array}$ & $\begin{array}{l}50 \mathrm{~mL} \text { prune juice }+ \text { two teaspoons cooked strawberries }+ \text { one sliced fresh } \\
\text { strawberry + one teaspoon frozen raspberries }\end{array}$ \\
\hline Black fruit & $\begin{array}{l}\text { Plum, blackberry, and black } \\
\text { currant }\end{array}$ & 50 mL Ribena ${ }^{\dagger}$ juice $^{g}$ \\
\hline Herbal & $\begin{array}{l}\text { Mint, sage, rosemary, pine, and } \\
\text { eucalyptus }\end{array}$ & $\begin{array}{c}50 \mathrm{~mL} \text { wine }+ \text { one drop eucalyptus oil }+10 \text { dried bits rosemary + one drop } \\
\text { "green herbaceous" aroma* }\end{array}$ \\
\hline $\begin{array}{l}\text { Canned green } \\
\text { vegetable }\end{array}$ & Asparagus and green bean & $\begin{array}{l}50 \mathrm{~mL} \text { wine }+ \text { one teaspoon canned asparagus + one teaspoon canned asparagus } \\
\text { juice + one teaspoon canned green bean juice }\end{array}$ \\
\hline Earthy/toast & $\begin{array}{c}\text { Dirty/dusty, leafy, straw, and } \\
\text { char/cigar }\end{array}$ & $\begin{array}{c}50 \mathrm{~mL} \text { wine + three dried leaves + one tablespoon dirt + one drop "toast" } \\
\text { aroma* }\end{array}$ \\
\hline Candy/confection & Candied cherry and cotton candy & $50 \mathrm{~mL}$ wine + two Swedish berries ${ }^{\ddagger}+3 / 4$ cup cotton candy ${ }^{\S}$ \\
\hline Floral & & $\begin{array}{c}50 \mathrm{~mL} \text { wine }+5 \mathrm{~cm} \text { of inside of Turkish delight } \text { bar }^{5}+\text { three Turkish delight } \\
\text { candies }\end{array}$ \\
\hline Leather/meat & & $50 \mathrm{~mL}$ wine + one drop "leather"* + one drop "smoky bacon"* \\
\hline
\end{tabular}

ratio of the standard over the internal standard was plotted against each analyte concentration to fit a quadratic equation where the intercept was set to zero. Recovery was calculated by measuring triplicate spiked samples after every 20 wines were measured.

2.5. Statistical Analysis. Analysis of variance (ANOVA), including one-way ANOVA [factors: VOC concentration], two-way ANOVA [factors: tasting replicate, winemaking replicate, and tasting replicate $*$ winemaking replicate interaction], and three-way ANOVA [factor=tasting replicate, judge, wine and tasting replicate $*$ judge, tasting replicate $*$ wine and judge $*$ wine interactions], was performed using XLSTAT software (Addinsoft, Paris, France), at $95 \%$ confidence interval $(\alpha<0.05)$. Sensory attributes that differed were separated by least significant difference (LSD) post hoc tests. Principal component analysis (PCA) (observations/variables: chemical compounds; supplementary variables: winemaking treatments; no rotation, PCA type: Pearson (n), type of biplot: correlation biplot/coefficient = automatic) and partial least squares regression analysis (PLS) (Y/quantitative variables: chemical compounds, X/quantitative variables: sensory attributes, algorithm: fast, stop conditions: automatic, cross-validation: Jackknife (LOO), variables: centre and reduce, confidence interval: 95\%) were also performed with XLSTAT software (Addinsoft, Paris, France).

\section{Results and Discussion}

3.1. Basic Must and Wine Parameters. The starting sugar concentration for each treatment is outlined in Table 2 . Wine grapes were dried to their target sugar concentrations and then delivered to the winery for processing, while control grapes were processed without drying. As expected, grape sugars increased with drying time to achieve the target parameters. The ethanol concentration in the final wines was not significantly different between yeast strains, except at $24.5^{\circ}$ Brix, where the EC1118 fermented wines yielded approximately $0.6 \% \mathrm{v} / \mathrm{v}$ more. Ethanol is an important component in the wine matrix, as it can elicit sweetness and bitterness [22, 23], and in higher ethanol matrices, greater sweetness may be required to mask its bitterness [24]. Furthermore, it can modify the perception of wine aroma compounds, specifically those in the woody and fruit category [25], and with an increasing concentration contributes burning and tingling sensations [26]. Ethanol is therefore able to modify the sensory profile of wines significantly, and this is considered later in the descriptive analysis study. Glycerol concentration was significantly higher in $\mathrm{CN} 1$ wines, while acetic acid and ethyl acetate were lower than that in EC1118 wines and significantly less acetaldehyde at the 26 and $27.5^{\circ}$ Brix treatments (details available in [13]).

\subsection{Descriptive Analysis and Principal Component Analysis.} A preliminary two-way ANOVA was conducted with tasting replicate and winemaking replicate as factors (data not shown) to determine whether the 18 wines (EC1118 control, $26.0^{\circ}$ Brix, and $27.5^{\circ}$ Brix, as well as $\mathrm{CN} 1$ control, $26.0^{\circ} \mathrm{Brix}$, and $27.5^{\circ}$ Brix and their respective triplicate winemaking replicates) could be collapsed to represent six treatments. Fermentation replicate was typically not significant $(p=0.319)$; therefore, we collapsed winemaking replicates for each of the six wine treatments in subsequent analyses. PLS (Figure 1) also adopts this model. A three-way ANOVA [factors = tasting replicate, judge, wine, and interactions] (Table S3) showed that 17 of the 22 attributes were significantly different between the wines. A principal component analysis (Figure 2) was then performed with all sensory 
TABLE 2: Metabolites and basic physiochemical characteristics in must and wine samples (mean \pm standard deviation) at each starting sugar concentration.

\begin{tabular}{|c|c|c|c|c|c|}
\hline \multicolumn{6}{|c|}{ Basic physiochemical characteristics } \\
\hline Treatment & Yeast & $\begin{array}{l}\text { Soluble solids } \\
\quad\left({ }^{\circ} \text { Brix }\right)\end{array}$ & $\begin{array}{c}\text { Must } \\
\text { Reducing sugar (g/ } \\
\mathrm{L})\end{array}$ & $\mathrm{pH}$ & $\begin{array}{c}\text { Titratable acidity }(\mathrm{g} / \mathrm{L} \\
\text { tartaric acid) }\end{array}$ \\
\hline \multirow{2}{*}{$\begin{array}{l}\text { Control }\left(21.5^{\circ} \text { Brix }\right) \\
\text { target }\end{array}$} & $\begin{array}{l}\text { S. cerevisiae } \\
\text { EC1118 }\end{array}$ & $21.5 \pm 0.5$ & $236 \pm 7 \mathrm{~d}^{*}$ & $3.41 \pm 0.07 \mathrm{~d}$ & $5.1 \pm 0.3 \mathrm{a}$ \\
\hline & S. uvarum CN1 & $21.7 \pm 0.5$ & $227 \pm 5 D^{*}$ & $3.43 \pm 0.01 \mathrm{C}$ & $4.9 \pm 0.3 \mathrm{~A}$ \\
\hline \multirow[t]{2}{*}{$24.5^{\circ}$ Brix target } & $\begin{array}{l}\text { S. cerevisiae } \\
\text { EC1118 }\end{array}$ & $24.3 \pm 0.1$ & $267 \pm 8 c$ & $3.76 \pm 0.02 b$ & $4.8 \pm 0.1 b$ \\
\hline & S. uvarum $\mathrm{CN} 1$ & $24.4 \pm 0.1$ & $269 \pm 7 \mathrm{C}$ & $3.71 \pm 0.03 \mathrm{~B}$ & $4.7 \pm 0.1 \mathrm{~A}, \mathrm{~B}$ \\
\hline \multirow[t]{2}{*}{$26.0^{\circ}$ Brix target } & $\begin{array}{l}\text { S. cerevisiae } \\
\text { EC1118 }\end{array}$ & $26.0 \pm 0.2$ & $293 \pm 4 b$ & $3.65 \pm 0.02 c$ & $4.4 \pm 0.1 \mathrm{c}$ \\
\hline & S. uvarum CN1 & $25.9 \pm 0.1$ & $290 \pm 4 B$ & $3.69 \pm 0.03 \mathrm{~B}$ & $4.5 \pm 0.1 \mathrm{~B}$ \\
\hline \multirow{2}{*}{$27.5^{\circ}$ Brix target } & $\begin{array}{l}\text { S. cerevisiae } \\
\text { EC1118 }\end{array}$ & $27.4 \pm 0.1$ & $313 \pm 3 a$ & $3.84 \pm 0.02 \mathrm{a}$ & $4.7 \pm 0.0 \mathrm{~b}$ \\
\hline & S. uvarum CN1 & $27.5 \pm 0.0$ & $315 \pm 6 \mathrm{~A}$ & $3.85 \pm 0.01 \mathrm{~A}$ & $4.6 \pm 0.1 \mathrm{~B}$ \\
\hline \multicolumn{6}{|c|}{ Wine } \\
\hline Treatment & Yeast & $\begin{array}{l}\text { Reducing sugar } \\
(\mathrm{g} / \mathrm{L})\end{array}$ & $\mathrm{pH}$ & $\begin{array}{l}\text { Titratable acidity }(\mathrm{g} / \mathrm{L} \\
\text { tartaric acid) }\end{array}$ & Ethanol (\% v/v) \\
\hline \multirow{2}{*}{$\begin{array}{l}\text { Control }\left(21.5^{\circ} \text { Brix }\right) \\
\text { target }\end{array}$} & $\begin{array}{l}\text { S. cerevisiae } \\
\text { EC1118 }\end{array}$ & $0.07 \pm 0.00 \mathrm{a}$ & $3.82 \pm 0.05 b$ & $8.5 \pm 0.3 a^{* * *}$ & $11.8 \pm 0.4 \mathrm{c}$ \\
\hline & S. uvarum $\mathrm{CN} 1$ & $0.07 \pm 0.00 \mathrm{~B}$ & $3.78 \pm 0.07 \mathrm{~B}$ & $6.7 \pm 0.1 \mathrm{C}^{* * *}$ & $11.5 \pm 0.2 \mathrm{~B}$ \\
\hline \multirow[t]{2}{*}{$24.5^{\circ}$ Brix target } & $\begin{array}{c}\text { S. cerevisiae } \\
\text { EC1118 }\end{array}$ & $0.11 \pm 0.07 \mathrm{a}$ & $3.87 \pm 0.01 b^{* *}$ & $6.5 \pm 0.1 \mathrm{~b}^{* * *}$ & $12.8 \pm 0.2 b^{*}$ \\
\hline & S. uvarum $\mathrm{CN} 1$ & $0.26 \pm 0.15 \mathrm{~B}$ & $3.77 \pm 0.03 \mathrm{~B}^{* *}$ & $7.7 \pm 0.1 \mathrm{~B}^{* * *}$ & $12.2 \pm 0.3 \mathrm{~B}^{*}$ \\
\hline \multirow[t]{2}{*}{$26.0^{\circ}$ Brix target } & $\begin{array}{l}\text { S. cerevisiae } \\
\text { EC1118 }\end{array}$ & $0.07 \pm 0.00 \mathrm{a}$ & $3.84 \pm 0.02 b^{* *}$ & $6.7 \pm 0.1 \mathrm{~b}^{* * *}$ & $12.9+0.2 b$ \\
\hline & S. uvarum $\mathrm{CN} 1$ & $0.07 \pm 0.00 \mathrm{~B}$ & $3.72 \pm 0.04 \mathrm{~B}^{* *}$ & $7.8 \pm 0.1 \mathrm{~A}^{* * *}$ & $13.1 \pm 0.7 \mathrm{~A}$ \\
\hline \multirow[t]{2}{*}{$27.5^{\circ}$ Brix target } & $\begin{array}{l}\text { S. cerevisiae } \\
\text { EC1118 }\end{array}$ & $0.09 \pm 0.03 \mathrm{a}^{*}$ & $4.02 \pm 0.01 \mathrm{a}^{* *}$ & $6.4 \pm 0.1 b^{* *}$ & $14.5 \pm 0.3 \mathrm{a}$ \\
\hline & S. uvarum CN1 & $2.35 \pm 1.23 \mathrm{~A}^{*}$ & $3.9 \pm 0.03 \mathrm{~A}^{* *}$ & $6.8 \pm 0.1 \mathrm{C}^{* *}$ & $14.0 \pm 0.6 \mathrm{~A}$ \\
\hline
\end{tabular}

Data adapted from [13]. Fermentations were conducted in triplicate, and each sample was tested in duplicate for all metabolites other than soluble solids. Lowercase (EC1118) and uppercase (CN1) letters indicate significant differences within the same yeast treatment determined by analysis of variance with the mean separation by Fisher's least significant difference (LSD; $p<0.05$ ). Asterisks $\left({ }^{*}=p<0.05,{ }^{* *}=p<0.01\right.$, and ${ }^{* * *} p<0.001$ ) indicate differences between yeast strains within a target Brix level as determined by Student's $t$-test

attributes and all wines, including winemaking replicates. The PCA explains $61.3 \%$ of the variation in the first two factors, which were retained. Winemaking replicates tended to group together, except for EC1118 Control Replicate 2 and CN1 26.0 Brix Replicate 2.

Generally, for this study, sensory terms that were generated by the panel should ideally represent both Cabernet franc typicity and wines made from partially dehydrated grapes. In a prior study [27], descriptors generated for Cabernet franc wines included stewed red fruits, empyreumatic (smoky and toast), spicy, vegetal, and animal (leather and stable), all of which were also identified here. Wines made from partially dehydrated grapes have been described aromatically with terms such as jam, cherries in alcohol, fresh fruit, herbal, tobacco, spice, and vanilla [28]. Interestingly, in the current study, the attributes red fruit (cooked/dried/fresh) aroma and flavour and floral and candy/confection aroma were associated with the control wines (representative of Cabernet franc table wines) for both yeast strains, which were negatively associated with herbal aroma and flavour, spice aroma and flavour earthy/toast aroma, and flavour (Figure 2). The sensorial impact of the yeast strain was clearly observed only at the highest starting sugar concentration $\left(27.5^{\circ} \mathrm{Brix}\right)$ as these wines were described with terms that were "green" (pepper, canned vegetable, and herbal) as well as terms that can be considered tertiary (earth, leather, and smoke) [29], while the lower Brix wines had higher intensity ratings of terms associated with the fruit. This is consistent with the findings of [30], where autochthonous yeast differed from selected yeasts sensorially in wines made with partially dehydrated grapes. Aroma attributes were not as clearly separated as flavour and oral sensations and prototypical taste sensations scores. The effect of volatile compounds on the wine sensory profile is complex, as the effects may be synergistic, additive, or suppressive [31]. Furthermore, with regard to the abundance of descriptors associated with the wines, most of the sensory attributes are correlated with the $27.5^{\circ}$ Brix wines, which contain the highest ethanol values. Meillon et al. [32] have reported that red wine with a higher alcohol content is perceived as more complex than lower alcohol wines, and panellists rated them as "persistent" and "with many aromas." In our study, the alcohol content in these $27.5^{\circ}$ Brix wines could contribute to the perceived complexity and 
Correlations on axes $t 1$ and $t 3$

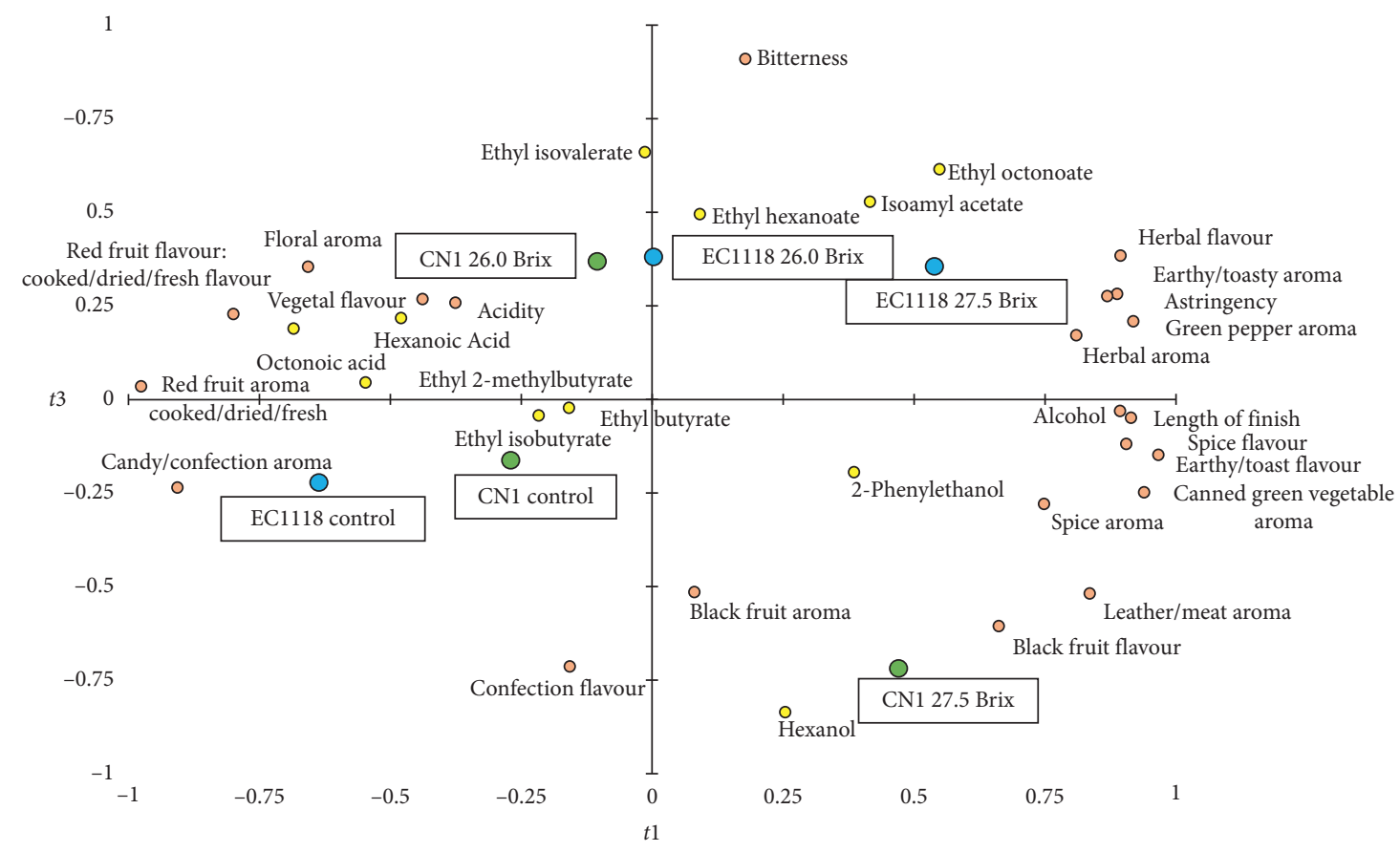

FIGURE 1: Impact of yeast strain and starting sugar concentration on the sensory and chemical profiles of Cabernet franc control (no dehydration) and wines made from partially dehydrated grapes as determined by partial least squares analysis.

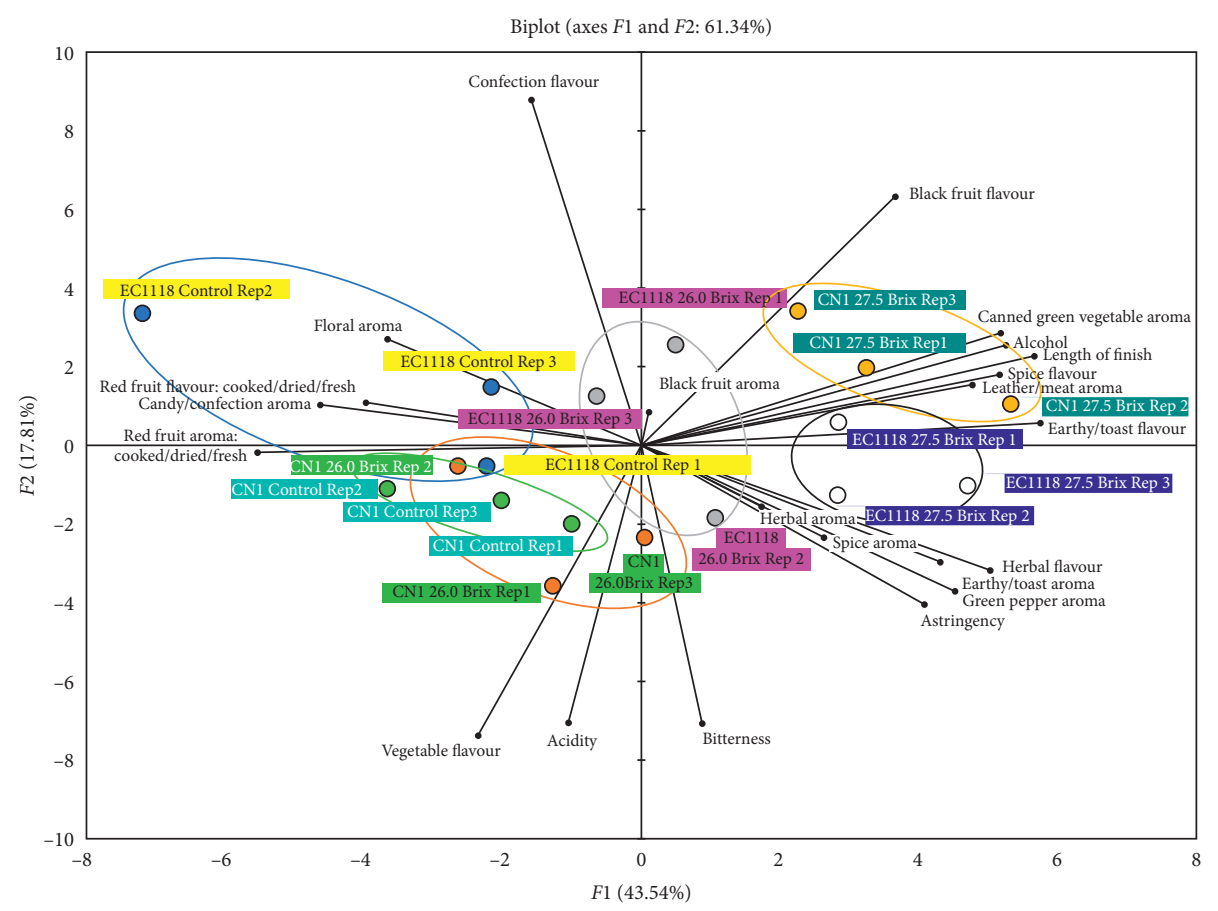

FIgURe 2: Principal components analysis biplot of descriptive analysis data for wines made from partially dehydrated grapes including winemaking replicates fermented with S. cerevisiae EC1118 and S. uvarum CN1 at different starting sugar concentrations (control $\left(21.5^{\circ}\right.$ Brix), $26.0^{\circ}$ Brix, and $27.5^{\circ}$ Brix). 
persistence (length of finish) and thus differentiate them from the other treatments.

Importantly, sensory attributes that are associated with oxidation compounds such as vinegar (acetic acid), nail polish remover (ethyl acetate), and bruised apple (acetaldehyde) [33] were not included on this list of descriptors, likely because the concentration of these compounds was below threshold levels (acetic acid in table wine $0.7-1.1 \mathrm{~g} / \mathrm{L}$, ethyl acetate $0.07-0.17 \mathrm{~g} / \mathrm{L}$ [34], and acetaldehyde $0.5 \mathrm{mg} / \mathrm{L}$ in $10 \%$ ethanol/water solution [1]). Even though there were significantly higher levels of oxidation compounds in wines made with EC1118, they were not detected sensorially.

Ellipses around data points group winemaking replicates from the same yeast and starting sugar concentration.

3.3. Volatile Organic Compound Analysis. The dehydration process itself makes a significant contribution to the aroma of appassimento style wine [14]. In agreement with our findings (Figures 3 and 4), prior research has also shown that wines made from dehydrated grapes contain high concentrations of acetic acid, hexanol, esters [35], isoamyl alcohols, 2-phenylethanol [36], ethyl acetate, phenylethyl alcohol [37], ethyl hexanoate, ethyl octanoate, and acetaldehyde [38].

The concentration of 2-phenylethanol in wines fermented with $\mathrm{CN} 1$ yeast is significantly higher for all treatments than EC1118 (Figure 3). Importantly, grape dehydration impacts amino acid catabolism (due to water stress), which can increase the concentration of higher alcohols [1]. Higher alcohols are important compounds in wine, and 2-phenylethanol is the most desirable phenolderived higher alcohol [33], as it can impart a rose-like aroma, while other higher alcohols have nondesirable aromas at high concentrations [39, 40]. Higher alcohols are also precursors to desirable ester production [40]. This class of compounds commonly accounts for about $50 \%$ of the aromatic constituents in wine, excluding ethanol [33]. Fusel alcohols are generally synthesized through metabolic pathways involving the formation of amino acids. The most common pathway, which accounts for more than $80 \%$ of the production [41], is the anabolic, which occurs during the biosynthesis of amino acids from hexose sugars. By this mechanism, sugar degradation leads to the formation of $\alpha$-keto acids which are decarboxylated to aldehydes and reduced to fusel alcohol. The other route for fusel alcohol synthesis - the Ehrlich pathway-is of lesser importance and involves the formation of new amino acids by catabolism of grape amino acids. In this mechanism, grape amino acids are deaminated to form $\alpha$-keto acids. These $\alpha$-keto acids are transformed into fusel alcohol following the steps above [42]. Prior research has reported that fermentation with S. uvarum strains (versus $S$. cerevisiae yeast strains) results in a greater concentration of some higher molecular weight alcohols, particularly 2-phenylethanol [43]. Additionally, Cordente et al. [40] have recently shown that higher alcohols tend to increase in higher Brix must, which is consistent with our findings.

Esters are condensation products of the carboxyl group of an organic acid and the hydroxyl group of an alcohol or a

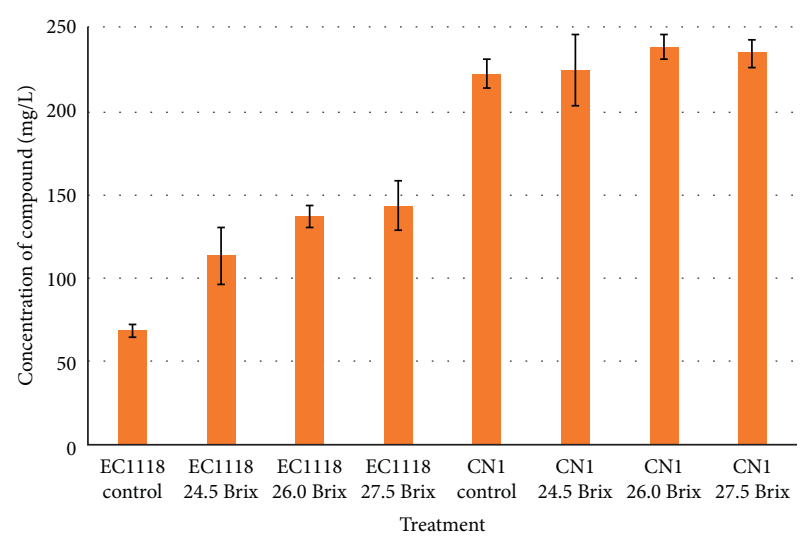

Figure 3: 2-Phenylethanol concentrations for control (no dehydration) and treatment wines made from partially dehydrated grapes fermented with $S$. cerevisiae EC1118 or S. uvarum CN1. Values are averages of 8 data points (duplicate measurements of 2 winemaking replicates, 2 bottles per replicate) \pm standard deviation.

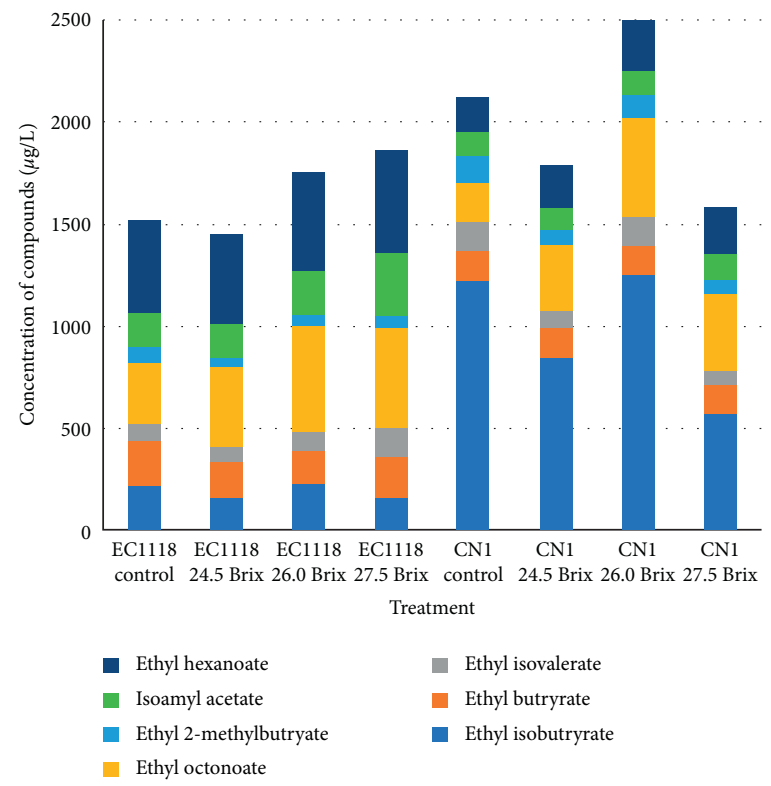

FIGURE 4: Concentration of selected volatile organic compounds for control (no dehydration) and wines made from partially dehydrated grapes fermented with $S$. cerevisiae EC1118 or S. uvarum CN1. Values are averages of 8 data points (duplicate measurements of 2 winemaking replicates, 2 bottles per replicate).

phenol. In wine, most of them are formed by yeast during fermentation after cell division has ceased, rather than originating from the grapes [44]. They contribute to the fruity aroma of young wines, and the choice of yeast has a significant influence on their production [45]. Our results show higher concentrations of ethyl isobutyrate in CN1 wines when compared to EC1118 wines. This compound has been identified as the most abundant ethyl ester of branched esters in red wines [46] and also contributes to a higher overall concentration of ethyl esters in wine fermented with our S. uvarum yeast. Ethyl isobutyrate is formed by the esterification of ethanol with the acids formed by yeast from corresponding amino acids or amino acid derivatives, such 
as ketoacids. Ethyl esters impart a "fruitiness" component to the wine but also can mask "vegetative" odours [47]. This may have occurred in our study as red fruit flavour (cooked/ dried/fresh) aroma and flavour were negatively correlated to canned green vegetable aroma (Figure 2). Isoamyl acetate is important to Passito (dried) wines, as it is a powerful odorant of wine, with a banana-like aroma, and is found at high levels in white wines made from dehydrated grapes [10]. Our results indicate that isoamyl acetate was present at suprathreshold concentrations in all wines, generally trending towards higher concentrations in EC1118 wines. Contrary to this finding, $S$. uvarum wines generally contain high concentrations of isoamyl acetate [48-50]. In this present study, even the control EC1118 wines had higher isoamyl acetate values than $\mathrm{CN} 1$ wines.

3.4. Volatile Fatty Acids. Hexanoic acid concentrations are as follows $(\mu \mathrm{g} / \mathrm{L})$ : control; EC1118: $3183.6 \pm 112.9^{\mathrm{a}}, \mathrm{CN} 1$ : $1160.2 \pm 66.9^{\mathrm{b}}, 24.5^{\circ}$ Brix; EC1118: $2501.7 \pm 134.6^{\mathrm{a}}, \mathrm{CN} 1$ : $1272.5 \pm 72.1^{\mathrm{b}}, \quad 26.0^{\circ}$ Brix; $\quad$ EC1118: $2394.4 \pm 88.4^{\mathrm{a}}, \quad \mathrm{CN} 1$ : $1148.2 \pm 220.4^{\mathrm{b}}, 27.5^{\circ}$ Brix; EC1118: $1955.13 \pm 161.5^{\mathrm{a}}, \mathrm{CN} 1$ : $990.2 \pm 46.9^{\mathrm{b}}$.

Octanoic acid concentrations were as follows: control; EC1118: $3230.9 \pm 192.4^{\mathrm{a}}$, CN1: $1616.7 \pm 108.6^{\mathrm{b}}, 24.5^{\circ}$ Brix; EC1118: $2560.3 \pm 55.8^{\mathrm{a}}, \mathrm{CN} 1: 1995.4 \pm 105.6^{\mathrm{b}}, 26.0^{\circ}$ Brix; EC1118: $2466.1 \pm 111.2^{\mathrm{a}}, \mathrm{CN} 1: 1889.04 \pm 126.5^{\mathrm{b}}, 27.5^{\circ} \mathrm{Brix}$; EC1118: $1848.4 \pm 221.0^{\mathrm{a}}, \mathrm{CN1}: 1430.0 \pm 71.8^{\mathrm{b}}$. Letters indicate significant differences within the same yeast treatment determined by the analysis of variance with the mean separation by Fisher's least significant difference (LSD; $p<0.05)$.

For both VFAs measured (hexanoic acid and octanoic acid), wines fermented with S. cerevisiae EC1118 had higher concentrations in all treatments. Fatty acid concentrations depend on several factors including type of yeast, fermentation temperature, and sugar content [51]. These compounds contribute fatty [2], powdery/greasy [52], sweet, cheesey [5], or a strong odour at relatively high concentrations [53]. Fatty acids are considered important to Amarone wine flavour [54] and are present in our wines at a concentration higher than the sensory threshold (Table S1). Importantly, these compounds vary with yeast strain. In wine made from partially dehydrated grapes, fatty acid levels are impacted by Botrytis cinerea infection as Botrytized wines made from partially dehydrated grapes contain lower fatty acid concentration than healthy wines [54].

The concentration of fatty acids reported in this study is aligned with values reported in the literature for appassimento style wines. Fedrizzi et al. [52] indicate $1546 \pm 11 \mu \mathrm{g} / \mathrm{L}$ for hexanoic acid and $1557 \pm 75 \mu \mathrm{g} / \mathrm{L}$ for octanoic acid in Amarone wines. Scacco et al. [2] report 2437-11350 $\mu \mathrm{g} / \mathrm{L}$ octanoic acid concentration in Amarone wines, and Loizzo et al. [55] report $5700 \mu \mathrm{g} / \mathrm{L}$ in Amarone wines. In young red wines, values of hexanoic acid of $853-3782 \mu \mathrm{g} / \mathrm{L}$ and octanoic acid of 562-4667 $\mu \mathrm{g} / \mathrm{L}$ are reported [5]. In this study, fatty acid concentrations generally decrease as starting sugar concentration increased for both yeast strains; thus, the association with these compounds is to the control wines (Figure 1).
3.5. Methoxypyrazines. Alkyl-methoxypyrazines (MPs) are a class of compounds identified in wine grapes that can have a positive impact on wine flavour at low levels, but at higher concentrations, they can impart undesirable "green" or "unripe" characteristics. MPs contribute typicity to some varietal wines such as Sauvignon blanc and Cabernet sauvignon and are elevated in under ripe fruit and in cooler climate viticultural areas [56]. MPs in wine can also arise from the Coccinellidae beetles, Harmonia axyridis, and Coccinella septempunctata when they are inadvertently incorporated in with the grapes during harvest [57], leading to a fault known as ladybug taint [58]. This taint has been previously noted in wines from the Ontario region. The key odour-active methoxypyrazines in wine are isobutyl methoxypyrazine (IBMP), isopropyl methoxypyrazine (IPMP), secbutyl methoxypyrazine (SBMP), and 2, 5-dimethyl-3-methoxypyrazine [20,57]. There has been anecdotal concern about utilizing Cabernet franc for producing appassimento style wine as it is a grape variety that may contain elevated concentrations of some MPs, particularly when it has not achieved optimal ripeness [59]. Specifically, MPs may be susceptible to further concentration from the drying process with possible negative impact on wine quality, particularly given the very low sensory detection thresholds for IPMP and IBMP in wine (0.3-10 ng/L) [60].

IPMP, SBMP, and IBMP are present at or above the threshold levels in all wines in our study (Figure 5) although they do not systematically change with the starting sugar concentration.

However, wine from the most dehydrated treatment $\left(27.5^{\circ}\right.$ Brix $)$ contain significantly higher concentrations of IBMP than the nondehydrated (control) wine for both yeasts. As IBMP is the most impactful grape-derived MP in wine, this suggests that some caution should be applied in the selection of grape variety and ripeness level when considering dehydrating fruit to $27.5^{\circ} \mathrm{Brix}$ and higher for appassimento style wine. Conversely, targeting a lower Brix level may be optimal with respect to the risk of increasing IBMP concentration in the final wines.

Prior research has shown the capacity for yeast strain to influence the MP composition of red wine, with evidence that the commercial S. cerevisiae Lalvin BM45 strain may produce IPMP [61]. In our study, IPMP concentration trends towards being higher in wines fermented with EC1118, but this is only significant in the $26.0^{\circ}$ Brix treatment where levels are approximately $75 \%$ higher than that of $\mathrm{CN} 1$. There are no differences observed in SBMP or IBMP between yeasts for any starting sugar level.

Sensory descriptors often associated with MPs such as green pepper and herbal aroma and flavour were used in the descriptive analysis although their intensity ratings were low (Table S4). There was a general trend of increasing intensity of these notes with increasing starting sugar concentration, which may be an added consideration when producing appassimento style wines in cool climate regions where they may be more likely to be on the "greener" spectrum of flavour if full physiological ripeness is not achieved. 


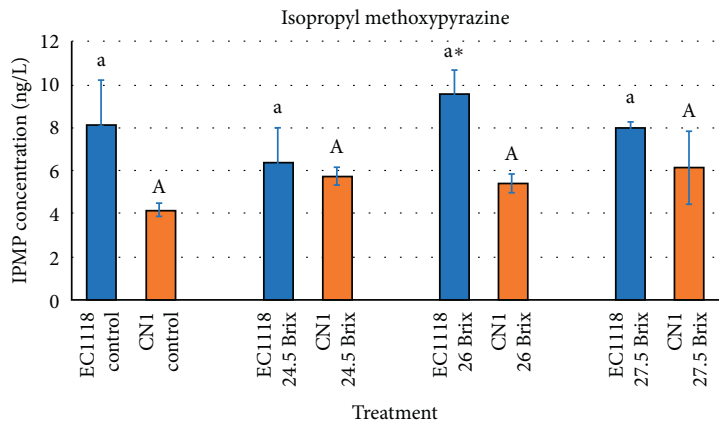

(a)

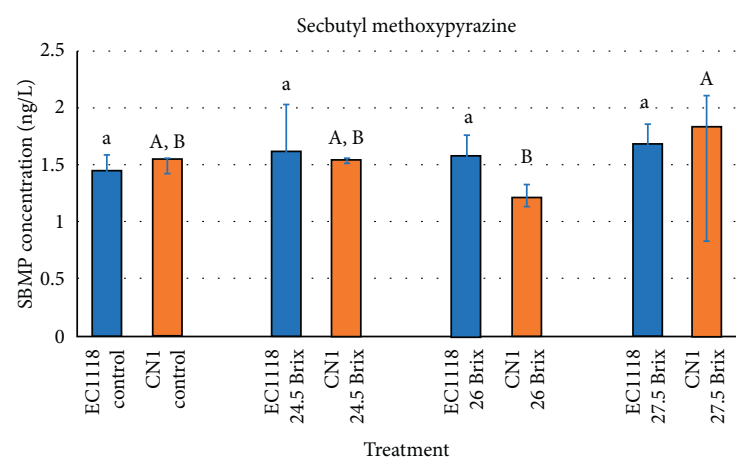

(b)

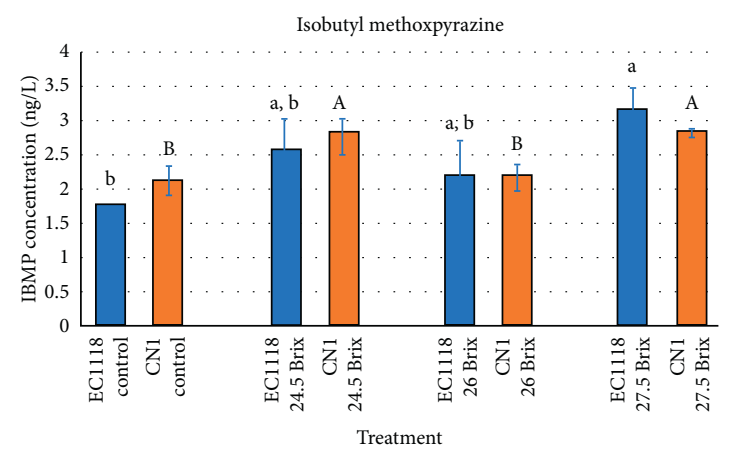

(c)

Figure 5: Concentrations of (a) IPMP, (b) SBMP, and (c) IBMP for control (no dehydration) and treatment wines made from partially dehydrated grapes fermented with $S$. cerevisiae EC1118 or S. uvarum CN1. Lowercase (EC1118) and uppercase (CN1) letters indicate statistical differences within the same yeast treatment determined by analysis of variance with mean separation by Fisher's least significant difference $(p<0.05)$. Asterisks $\left({ }^{*} p<0.05,{ }^{* *} p<0.01\right.$, and $\left.{ }^{* * *} p<0.001\right)$ indicate significant differences between yeast strains at the indicated dehydration target as determined by Student's $t$-test.

3.6. Partial Least Square (PLS) Regression Analysis. In order to understand the relationship between two key data sets in this study (sensory properties and chemical composition), multivariate statistical methods are often used to determine which volatiles best model the sensory profiles [62]. Thus, the authors utilized PLS as it predicts the explanatory variables (VOC and VFA data) from response variables (sensory analysis) [63].

The PLS (Figure 1) of the 22 sensory attributes and 11 VOC and VFA compounds is described below. The cumulated $\mathrm{R}^{2} \mathrm{Y}$ and $\mathrm{R}^{2} \mathrm{X}$ indexes that correspond to the correlations between the explanatory $(x)$ and dependent $(y)$ variables explain $80.0 \%(x)$ and $90.2 \%(y)$ of variability. PLS indicates that both control wines are associated with candy/ confection and red fruit aromas and ethyl isobutyrate. These sensory attributes of the $\mathrm{CN} 1$ control wines appear to be due to the relative abundance of ethyl isobutyrate, ethyl butyrate, and ethyl 2-methylbutyrate based on their groupings on the plot. Conversely, S. cerevisiae EC1118 $27.5^{\circ}$ Brix is associated with herbal flavour, earthy/toasty aroma, astringency, green pepper aroma, and herbal aroma, correlated with ethyl octanoate and isoamyl acetate and inversely related to the $\mathrm{CN} 1$ control attributes previously described.
S. uvarum CN1 $27.5^{\circ}$ Brix is discriminated from other wines by its position in the lower right quadrant, where it is correlated with black fruit flavour, leather/meat aroma, and black fruit aroma and associated with hexanol and 2-phenylethanol. The association with spice aroma and flavour (Figure 1) may be due to the 2-phenylethanol content [64] or other unquantified metabolites. The control wines from each yeast strain and the $26.0^{\circ}$ Brix wines from each yeast strain are positioned relatively close to each other, suggesting they have similar sensory profiles and are associated with similar volatiles. In contrast, yeast strain is most discriminating in the high $\left(27.5^{\circ} \mathrm{Brix}\right)$ wines, whereas differential VOC profiles appear largely responsible.

\section{Conclusions}

Both sensory profiles and chemical composition of the wines made from partially dehydrated grapes from different yeast strains were assessed in this study. Starting sugar concentration and most significantly yeast strain selection had an impact on chemical and sensory profiles. Increased complexity (longer the length of finish and more descriptive attributes) was associated with wines fermented at the 
highest starting sugar concentration. Furthermore, higher Brix wines contain elevated concentrations of compounds such as ethyl hexanoate, ethyl isovalerate, ethyl octanoate, 2phenylethanol, and hexanol, all varying with the yeast strain. In particular, the autochthonous $\mathrm{CN} 1$ had elevated concentrations of 2-phenylethanol and ethyl isobutyrate when compared to the commercial yeast, EC1118. Sensorially, the interaction between yeast strain and starting sugar concentration has the most notable difference at $27.5^{\circ} \mathrm{Brix}$, and resultant wines are differentiated from other starting sugar concentrations.

This is the first time appassimento style wine made in Ontario at varying starting sugar concentrations and fermented with indigenous yeast have been sensorially and chemically profiled. This research contributes to the characterization of CN1. This information can be used to assist with the optimization of winemaking practices to enhance the wine quality when fermenting partially dehydrated grapes.

\section{Data Availability}

Data will be made available on the Brock Library Digital Repository at http://www.dr.library.brocku.ca.

\section{Conflicts of Interest}

The authors declare that there are no conflicts of interest regarding the publication of this paper.

\section{Acknowledgments}

The authors would like to acknowledge Shufen Xu for her assistance with GC-MS analysis. This project was funded by the Ontario Research Fund - Research Excellence grant (ORF RE-05-038) and a grant from the Natural Sciences and Engineering Research Council of Canada (NSERC 2388722012).

\section{Supplementary Materials}

Table S1: categories, CAS numbers, odour descriptors, and sensory thresholds $(\mathrm{mg} / \mathrm{L})$ of all volatile organic compounds and volatile fatty acids measured in wines made from partially dehydrated grapes. Table S2: volatile aroma compounds, retention times, target and confirming ions, standard curves, \% recovery, calibration ranges, and \% coefficient of variation (CV). Table S3: output of 3-way ANOVA (factors = tasting replicate, judge, wine] and interactions amongst factors $(p<0.05)$. Table S4: mean intensity ratings for each sensory descriptive attribute. Lowercase letters indicate statistical differences within the same attribute with differences between winemaking treatments (yeast strain and starting sugar concentration) determined by analysis of variance with mean separation by Fisher's least significant difference (LSD; $p<0.05)$. (Supplementary Materials)

\section{References}

[1] H. Guth, "Quantitation and sensory studies of character impact odorants of different white wine varieties," Journal of Agricultural and Food Chemistry, vol. 45, no. 8, pp. 3027-3032, 1997.

[2] A. Scacco, C. M. Lanza, A. Mazzaglia, G. Tripodi, G. Dima, and A. Verzera, "Correlation between aroma compounds and sensory properties of passito Malvasia wines produced in Sicily," American Journal of Enology and Viticulture:, vol. 65, pp. 260-265, 2010.

[3] D. Torrea, C. Varela, M. Ugliano, C. Ancin-Azpilicueta, I. Leigh Francis, and P. A. Henschke, "Comparison of inorganic and organic nitrogen supplementation of grape juice - effect on volatile composition and aroma profile of a Chardonnay wine fermented with Saccharomyces cerevisiae yeast," Food Chemistry, vol. 127, no. 3, pp. 1072-1083, 2011.

[4] K.-S. Yoo, J. E. Kim, J. S. Moon et al., "Evaluation of a volatile aroma preference of commercial red wines in Korea: sensory and gas chromatography characterization," Food Science and Biotechnology, vol. 19, no. 1, pp. 43-49, 2010.

[5] I. L. Francis and J. L. Newton, "Determining wine aroma from compositional data," Australian Journal of Grape and Wine Research, vol. 11, no. 2, pp. 114-126, 2005.

[6] J. Wang, D. L. Capone, K. L. Wilkinson, and D. W. Jeffery, "Chemical and sensory profiles of rosé wines from Australia," Food Chemistry, vol. 196, pp. 682-693, 2016.

[7] M. González-Álvarez, R. Noguerol-Pato, C. González-Barreiro, B. Cancho-Grande, and J. Simal-Gándara, "Sensory quality control of young vs. Aged sweet wines obtained by the techniques of both postharvest natural grape dehydration and fortification with spirits during vinification," Food Analytical Methods, vol. 6, no. 1, pp. 289-300, 2013.

[8] V. Costantini, A. Bellincontro, D. De Santis, R. Botondi, and F. Mencarelli, "Metabolic changes of malvasia grapes for wine production during postharvest drying," Journal of Agricultural and Food Chemistry, vol. 54, no. 9, pp. 3334-3340, 2006.

[9] M. T. Frangipane, S. Torresi, D. D. Santis, and R. Massantini, "Effect of drying process in chamber at controlled temperature on the grape phenolic compounds," Italian Journal of Food Science, vol. 24, pp. 1-7, 2012.

[10] M. Giordano, L. Rolle, G. Zeppa, and V. Gerbi, "Chemical and volatile composition of three Italian sweet white Passito wines," OENO One, vol. 43, no. 3, pp. 159-170, 2009.

[11] D. E. Urcan, S. Giacosa, F. Torchio et al., "Fortified' wines volatile composition: effect of different postharvest dehydration conditions of wine grapes cv. Malvasia moscata (Vitis vinifera L.)," Food Chemistry, vol. 219, pp. 346-356, 2017.

[12] J. Kelly, F. Yang, L. Dowling et al., "Characterization of Saccharomyces bayanus CN1 for fermenting partially dehydrated grapes grown in cool climate winemaking regions," Fermentation, vol. 4, pp. 1-13, 2018.

[13] J. M. Kelly, S. A. van Dyk, L. K. Dowling et al., "Saccharomyces uvarum yeast isolate consumes acetic acid during fermentation of high sugar juice and juice with high starting volatile acidity," OENO One, vol. 54, pp. 199-211, 2020.

[14] A. Bellincontro, F. Matarese, C. D’Onofrio, D. Accordini, E. Tosi, and F. Mencarelli, "Management of postharvest grape withering to optimise the aroma of the final wine: a case study on Amarone," Food Chemistry, vol. 213, pp. 378-387, 2016.

[15] P. Romano, "Function of yeast species and strains in wine flavour," International Journal of Food Microbiology, vol. 86, no. 1-2, pp. 169-180, 2003. 
[16] F. Mencarelli and A. Bellincontro, "Recent advances in postharvest technology of the wine grape to improve the wine aroma: recent advances in postharvest technology of wine grape to improve wine aroma," Journal of the Science of Food and Agriculture, vol. 100, no. 14, pp. 5046-5055, 2018.

[17] G. Fleet, "Yeast interactions and wine flavour," International Journal of Food Microbiology, vol. 86, no. 1-2, pp. 11-22, 2003.

[18] D. Kontkanen, D. Inglis, G. Pickering, and A. Reynolds, "Effect of yeast inoculation rate, acclimatization, and nutrient addition on Icewine fermentation," American Journal of Enology and Viticulture, vol. 55, pp. 363-370, 2004.

[19] R. C. Hootman, Manual on Descriptive Analysis Testing for Sensory Evaluation, American Society for Testing and Materials, Baltimore, MD, USA, 1992.

[20] A. Botezatu, B. Kemp, and G. Pickering, "Chemical and sensory evaluation of silicone and polylactic acid-based remedial treatments for elevated methoxypyrazine levels in wine," Molecules, vol. 21, no. 9, p. 1238, 2016.

[21] F. Zhu, B. Du, and J. Li, "Aroma compounds in wine," in Grape and Wine Biotechnology, Chapter 12, pp. 273-283, 2016.

[22] M. Thibodeau and G. Pickering, "The role of taste in alcohol preference, consumption and risk behavior," Critical Reviews in Food Science and Nutrition, vol. 59, pp. 1-17, 2017.

[23] S. Vidal, P. Courcoux, L. Francis et al., "Use of an experimental design approach for evaluation of key wine components on mouth-feel perception," Food Quality and Preference, vol. 15, no. 3, pp. 209-217, 2004.

[24] Z. Panovská, A. Šedivá, M. Jedelská, and J. Pokorný, "Effect of ethanol on interactions of bitter and sweet tastes in aqueous solutions," Czech Journal of Food Sciences, vol. 26, no. 2, pp. 139-145, 2008.

[25] E. Le Berre, B. Atanasova, D. Langlois, P. Etiévant, and T. Thomas-Danguin, "Impact of ethanol on the perception of wine odorant mixtures," Food Quality and Preference, vol. 18, no. 6, pp. 901-908, 2007.

[26] A. A. Nolden and J. E. Hayes, "Perceptual qualities of ethanol depend on concentration, and variation in these percepts associates with drinking frequency," Chemosensory Perception, vol. 8, no. 3, pp. 149-157, 2015.

[27] Y. Cadot, S. Caillé, A. Samson, G. Barbeau, and V. Cheynier, "Sensory representation of typicality of Cabernet franc wines related to phenolic composition: impact of ripening stage and maceration time," Analytica Chimica Acta, vol. 732, pp. 91-99, 2012.

[28] D. Accordini, "Amarone," in Sweet, Reinforced, and Fortified Wines: Grape Biochemistry, Technology, and Vinification, F. Mencarelli and P. Tonutti, Eds., pp. 189-203, WileyBlackwell, Hoboken, NJ, USA, 2013.

[29] Q. Wang and C. Spence, "Wine complexity: an empirical investigation," Food Quality and Preference, vol. 68, pp. 1-23, 2018.

[30] N. López de Lerma, T. García-Martínez, J. Moreno, J. C. Mauricio, and R. A. Peinado, "Volatile composition of partially fermented wines elaborated from sun dried Pedro Ximénez grapes," Food Chemistry, vol. 135, no. 4, pp. 2445-2452, 2012.

[31] M. McKay, F. Bauer, V. Panzeri, and A. Buica, "Testing the sensitivity of potential panelists for wine taint compounds using a simplified sensory strategy," Foods, vol. 7, no. 11, p. 176, 2018.

[32] S. Meillon, D. Viala, M. Medel, C. Urbano, G. Guillot, and P. Schlich, "Impact of partial alcohol reduction in Syrah wine on perceived complexity and temporality of sensations and link with preference," Food Quality and Preference, vol. 21, no. 7, pp. 732-740, 2010.

[33] R. S. Jackson, Wine Science: Principles and Applications, Elsevier/Academic Press, Boston, MA, USA, 2008.

[34] M. A. Cliff and G. J. Pickering, "Determination of odour detection thresholds for acetic acid and ethyl acetate in ice wine," Journal of Wine Research, vol. 17, no. 1, pp. 45-52, 2006.

[35] A. Bellincontro, D. De Santis, R. Botondi, I. Villa, and F. Mencarelli, "Different postharvest dehydration rates affect quality characteristics and volatile compounds of Malvasia, Trebbiano and Sangiovese grapes for wine production," Journal of the Science of Food and Agriculture, vol. 84, no. 13, pp. 1791-1800, 2004.

[36] J. J. Moreno, F. Cerpa-Calderón, S. D. Cohen, Y. Fang, M. Qian, and J. A. Kennedy, "Effect of postharvest dehydration on the composition of pinot noir grapes (Vitis vinifera L.) and wine," Food Chemistry, vol. 109, no. 4, pp. 755-762, 2008.

[37] M. J. Ruiz, L. Zea, L. Moyano, and M. Medina, "Aroma active compounds during the drying of grapes cv. Pedro Ximenez destined to the production of sweet Sherry wine," European Food Research and Technology, vol. 230, no. 3, pp. 429-435, 2010.

[38] I. Budic-Leto, G. Zdunic, M. Banovic, K. Kovacevic-Ganic, I. Tomic-Potrebujes, and T. Lovric, "Fermentative aroma compounds and sensory descriptors of traditional Croatian dessert wine Prosek from Plavac Mali cv," Food Technology and Biotechnology, vol. 48, pp. 530-537, 2010.

[39] P. X. Etiévant, "Wine. In volatile compounds in food and beverages," in Food Science and Technology, H. Maarse, Ed., pp. 483-546, Marcel Dekker Inc., New York, NY, USA, 1991.

[40] A. G. Cordente, M. Solomon, A. Schulkin et al., "Novel wine yeast with ARO4 and TYR1 mutations that overproduce 'floral' aroma compounds 2-phenylethanol and 2-phenylethyl acetate," Applied Microbiology and Biotechnology, vol. 102, no. 14, pp. 5977-5988, 2018.

[41] M. A. Nesbit, H. J. Tobias, T. Brenna, G. L. Sacks, and A. K. Mansfield, "Quantifying the contribution of grape hexoses to wine volatiles by high-precision [U13C]-glucose tracer studies," Journal of Agricultural and Food Chemistry, vol. 62, pp. 6820-6827, 2014.

[42] E. C.-H. Chen, "The relative contribution of Ehrlich and biosynthetic pathways to the formation of fusel alcohols," Journal of the American Society of Brewing Chemists, vol. 36, no. 1, pp. 39-43, 1978.

[43] I. Masneuf-Pomarède, M. Bely, P. Marullo, A. LonvaudFunel, and D. Dubourideau, "Reassessment of phenotypic traits for Saccharomyces bayanus var. uvarum wine yeast strains," International Journal of Food Microbiology, vol. 139, pp. 79-86, 2010.

[44] A. Tsakiris, S. Kallithraka, and Y. Kourkoutas, "Grape brandy production, composition and sensory evaluation," Journal of the Science of Food and Agriculture, vol. 94, no. 3, pp. 404-414, 2014.

[45] A. Rapp and H. Mandery, "Wine aroma," Experientia, vol. 42, no. 8, pp. 873-884, 1986.

[46] G. Antalick, M.-C. Perello, and G. de Revel, "Esters in wines: new insight through the establishment of a database of French wines," American Journal of Enology and Viticulture, vol. 65, no. 3, pp. 293-304, 2014.

[47] K. Bindon, C. Varela, J. Kennedy, H. Holt, and M. Herderich, "Relationships between harvest time and wine composition in Vitis vinifera L. cv. Cabernet Sauvignon 1. Grape and wine 
chemistry," Food Chemistry, vol. 138, no. 2-3, pp. 1696-1705, 2013.

[48] J. Stribny, A. Gamero, R. Pérez-Torrado, and A. Querol, "Saccharomyces kudriavzevii and Saccharomyces uvarum differ from Saccharomyces cerevisiae during the production of aroma-active higher alcohols and acetate esters using their amino acidic precursors," International Journal of Food Microbiology, vol. 205, pp. 41-46, 2015.

[49] L. Bertolini, C. Zambonelli, P. Guidici, and L. Castellari, "Higher alcohol production by crytolerant Saccharomyces strains," American Journal of Enology and Viticulture, vol. 47, pp. 343-345, 1996.

[50] C. Massoutier, H. Alenandre, H. Feuillat, and C. Charpentnier, "Isolation and characterization of cryotolerant Saccharomyces strains," Vitis, vol. 37, pp. 55-59, 1998.

[51] P. Schreirer, "Flavor composition of wines-a review," Critical Reviews in Food Science and Nutrition, vol. 12, pp. 59-111, 1979.

[52] B. Fedrizzi, G. Zapparoli, F. Finato et al., "Model aging and oxidation effects on varietal, fermentative, and sulfur compounds in a dry botrytized red wine," Journal of Agricultural and Food Chemistry, vol. 59, no. 5, pp. 1804-1813, 2011.

[53] J. V. Gil, J. J. Mateo, M. Jiménez, A. Pastor, and T. Huerta, "Aroma compounds in wine as influenced by apiculate yeasts," Journal of Food Science, vol. 61, no. 6, pp. 1247-1250, 1996.

[54] M. Azzolini, E. Tosi, S. Faccio, M. Lorenzini, S. Torriani, and G. Zapparoli, "Selection of Botrytis cinerea and Saccharomyces cerevisiae strains for the improvement and valorization of Italian passito style wines," FEMS Yeast Research, vol. 13, no. 6, pp. 540-552, 2013.

[55] M. R. Loizzo, M. Bonesi, G. Di Lecce et al., "Phenolics, aroma profile, andIn VitroAntioxidant activity of Italian dessert passito wine from saracena (Italy)," Journal of Food Science, vol. 78, no. 5, pp. C703-C708, 2013.

[56] G. Pickering, A. Blake, G. Soleas, and D. Inglis, "Remediation of wine with elevated concentrations of 3-alkyl-2-methoxyprazines using cork and synthetic closures," Journal of Food, Agriculture and Environment, vol. 8, pp. 97-101, 2010.

[57] A. Botezatu and G. J. Pickering, "Determination of ortho- and retronasal detection thresholds and odor impact of 2, 5-dimethyl-3-methoxypyrazine in wine," Journal of Food Science, vol. 77, no. 11, pp. S394-S398, 2012.

[58] G. Pickering, J. Lin, R. Riesen, A. Reynolds, I. Brindle, and G. Soleas, "Influence of Harmonia axyridis on the sensory properties of white and red wine," American Journal of Enology and Viticulture, vol. 55, pp. 154-159, 2004.

[59] P. Darriet, C. Thibon, and D. Dubourdieu, "Aroma and aroma precursors in grape berry," The Biochemistry of the Grape Berry, Chapter 6, pp. 111-136, 2012.

[60] G. J. Pickering, A. Karthik, D. Inglis, M. Sears, and K. Ker, "Determination of ortho- and retronasal detection thresholds for 2-isopropyl-3-methoxypyrazine in wine," Journal of Food Science, vol. 72, no. 7, pp. S468-S472, 2007.

[61] G. J. Pickering, M. Spink, Y. Kotseridis et al., "Yeast strain affects 3-isopropyl-2-methoxypyrazine concentration and sensory profile in Cabernet Sauvignon wine," Australian Journal of Grape and Wine Research, vol. 4, pp. 230-237, 2008.

[62] A. C. Noble and S. E. Ebeler, "Use of multivariate statistics in understanding wine flavor," Food Reviews International, vol. 18, no. 1, pp. 1-20, 2002.

[63] M. Tenenhaus and V. E. Vinzi, "PLS regression, PLS path modeling and generalized Procrustean analysis: a combined approach for multiblock analysis," Journal of Chemometrics, vol. 19, no. 3, pp. 145-153, 2005.

[64] T. Acree and H. Arn, "Odorant database," 2004, http://www. flavornet.org. 